\title{
Editorial
}

\section{Why Don't Doctors and Nurses Wash Their Hands?}

\author{
Peter Heseltine, MD
}

For almost 150 years healthcare workers have been taught that cross-infections are transmissible but not contagious and that the most effective way to prevent these cross-infections is to wash their hands before and after every patient contact.1,2 But, they don't do it. They don't merely not do it every time, they don't do it most of the time and sometimes not even when it might be most expected, as when caring for an intensive care unit (ICU) or emergency room patient. ${ }^{3,4} \mathrm{~A}$ brief observation in almost any clinic or hospital will confirm these lapses. Why don't physicians and nurses follow this most basic care practice?

Some years ago, while visiting a foreign military hospital, my colleague asked, half-jokingly, the purpose of the armed soldier stationed outside the ICU. We were told quite seriously that the sergeant had instructions to arrest anyone entering the unit who did not don a gown and gloves after washing their hands. We were impressed less by the show of force than by the example of commitment to a tenet of infection control we professed to be essential. But, we asked ourselves, are the lives of our ICU patients less important than these, that we cannot muster the same enthusiasm at home?

Why don't physicians and nurses wash their hands? Is it that we really don't believe that hand washing works? If we didn't believe in the spread of disease on our hands, why did we adopt the use of gloves so quickly in the acquired immunodeficiency syndrome era? And why do we not change those gloves-always-between patient contacts? The reasons that come to mind do not seem very compatible with our professional ethics or sworn oaths.

Maybe we don't believe it's necessary. For a few years after the introduction of penicillin, it seemed possible that all infections might be vanquished by antibiotics, but, in less than a blink of evolution's eye, the promise was gone, replaced by organisms resistant to all known antimicrobials, such as vancomycin-resistant enterococci, a leading cause of mortality in liver transplant patients. ${ }^{5}$

Perhaps it has to do with our expectation of successful outcomes for our patients. My pediatric colleagues are both enthusiastic about their patients and, usually, enthusiastic about the outcomes. Although not perfect by any measure, in general they practice better infection control. Maybe the daunting task of believing a tiny $800-\mathrm{g}$ baby will survive to become a fulfilled adult requires a different perspective on the contribution of each small act of care.

The authors of an article in this issue give us some measure of how much healthcare workers do care when challenged and how science is best applied. ${ }^{6}$ The article is about the scientific examination of an electronic faucet. The authors found one that didn't work as advertised and that may have enhanced the growth of pathogenic bacteria. They warn us not to rely on technology as an answer to our problems. What they don't tell you is that, during this time, they were in the aftermath of a terrible flood and were rebuilding their town-from scratch and memories of what was good. They used technology to measure how safe their hospital was for their patients. They did not use the technology as a substitute for care. That they carried out this study at a time of great hardship is extraordinary.

There are healthcare workers throughout the developing world who work under the same or worse conditions. And in the United States there are some who also work under these conditions. They work in crowded public and community hospitals and clinics with few resources and antiquated systems. It's hard to believe in-or to achieveexcellent medical outcomes when you don't have the space, the supplies, or the trained people to succeed. They are told that new technology will make it all work; but, it is not about the technology, it's about how much excellence you expect.

Healthcare workers' expectations of excellence are perhaps not sufficiently part of modern medicine. A recent report by the Institute of Medicine tells us more than we wanted to know about our performance. ${ }^{7}$ As healthcare costs more and the budgets contract, there has emerged a philosophy of the reversed Field of Dreams. If we don't build it, they won't come. Maybe they are right, but it numbs the soul and loses sight of excel- 
lence. Excellence creates hope. It's why people who are sick come for care. Each of us hopes that our physician or nurse will see us as a person for whom the individual quality of life is the paramount goal. This is the quality of medicine, the rationale.

North Dakota's experience teaches us about hope and the role of science as a tool. You can build a good hospital from the ruins of the river, if you have the right people and if you expect the quality your own family deserves.

Is it lack of hope that makes us pass by the hand basin? Where is the search for excellence that brought us to the profession? There are companies in America who have adopted Six Sigma as their quality goal. Six Sigma is an error rate of 3.4 per billion opportunities. It's an extraordinary goal, but one that makes sense for medical care and to epidemiologists. If you are only $99 \%$ accurate and you treat 60 million patients a year-a conservative figure for US healthcare-you have given almost 60,000 patients inappropriate care. The Institute of Medicine is even more blunt about the statistics: perhaps as many as 98,000 people die each year due to preventable medical errors.

It's time for us to require the same level of quality in healthcare that we require from our automobiles, our air travel, our recreational equipment, and our electrical appli- ances. Technology can help us accomplish this, but, more likely, technology will measure where we succeed and where we fail. This is the epidemiologist's contribution. Let's take the lesson of Grand Forks to focus on our patients and rebuild medical care using the tools of technology, epidemiology, and science, with the goal of excellence. We may not succeed for all, but we certainly can fulfill our obligation to each patient.

\section{REFERENCES}

1. Gyorgyey FA. Puerperal Fever 1847-1861. New Haven, CT: Yale University; 1968:96-121. Thesis.

2. Garner JS, Favero MS. CDC guideline for handwashing and hospital environmental control, 1985. Infect Control 1986;7:231-243.

3. Pittet D, Mourouga P, Perneger TV. Compliance with handwashing in a teaching hospital. Infection Control Program. Ann Intern Med 1999;130:126-130.

4. Albert RK, Condie F. Hand-washing patterns in medical intensive-care units. $N$ Engl J Med 1981;304:1465-1466.

5. Newell KA, Millis JM, Arnow PM, Bruce DS, Woodle ES, Cronin DC, et al. Incidence and outcome of infection by vancomycin-resistant Enterococcus following orthotopic liver transplantation. Transplantation 1998;65:439-442.

6. Hargreaves J, Shireley L, Hansen S, Bren V, Fillipi G, Lacher C, et al. Bacterial contamination associated with electronic faucets: a new risk for healthcare facilities. Infect Control Hosp Epidemiol 2001;22:202-205.

7. Kohn LT, Corrigan JM, Donaldson MS. To Err Is Human: Building a Safer Health System. Washington, DC: National Academy Press; 2000. 


\section{All The Facts For Your Immunization Program}

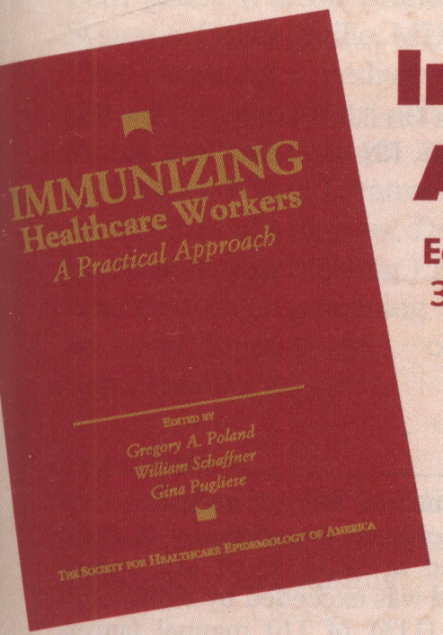

Both textbooks are an official publication of

The Society for Healthcare Epidemiology of America (SHEA).

Immunizing Healthcare Workers: A Practical Approach

Edited by Gregory A. Poland, MD; William Schaffner, MD; Gina Pugliese, RN, MS 300 pp, Hard Cover, 2000, ISBN 1-55642-450-7, Order \# 14507, \$109.00

Immunizing Healthcare Workers: A Practical Approach is the first complete resource for dealing with the immunization of healthcare workers. You can find all of the latest information on successfully and safely implementing or updating your immunization program in this landmark book.

Inside you will find that for each of the vaccine-preventable diseases among workers, there is a discussion of disease risks in the healthcare setting, vaccine recommendations, special administration strategies, safety issues, discussion of unresolved issues, and answers to commonly asked questions. There are also case studies of sample programs in specific settings.
This phenomenal book contains the latest recommendations from the US Public Health Service Advisory Committees, Healthcare Infection Control Practices Advisory Committee (HICPAC), and the Advisory Committee on Immunization Practices (ACIP)

Read how the experts overcame obstacles while setting up immunization programs in their healthcare settings. With over 45 contributors to 32 chapters, Immunizing Healthcare Workers: A Practical Approach is an essential source for the latest information necessary to implement an effective immunization program.

\section{Some Case Study Topics:}

Immunizing Providers and Staff in Physicians' Offices

Vaccination of Healthcare Workers in Long-Term Care Facilities for the Elderly

Immunization of Affiliating Students and Contract Home Healthcare Workers

Immunization Strategies for Home Healthcare Personnel
- Immunization of Workers with Altered Host Defenses

- Vaccinating Unimmunized and Partially Immunized Workers

- Assessing Immunity and Exposures: Using a Computerized Surveillance System

- Managing Information in an Immunization Program

- The Internet: A Quick Guide to Vaccine \& Immunization Information

\section{ORDER FORM}

ind me ___ copies of Immunizing Healthcare Workers: A Practical Approach 14507 ) at $\$ \mathbf{1 0 9 . 0 0}$ each.

end me ___ copies of A Practical Handbook for Hospital Epidemiologists $\# 13020)$ at $\$ 65.00$ each.

idents add $6 \%$ sales tax $\$$

Handling $\$ 4.50$

Total \$

State: Zip: Fax: renclosed (Payable to SLACK Incorporated) VISA

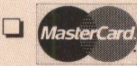

\section{A/so Available}

A Practical Handbook for Hospital Epidemiologists Edited by: Loreen A. Herwaldt, MD and co-edited by Michael D. Decker, MD, MPH

448 pp, Soft Cover, 1998, ISBN 1-55642-302-0,

Order \# 13020, $\$ 65.00$

A Practical Handbook for Hospital Epidemiologists is the most complete source for practical advice on hospital epidemiology. It is intended to be a pragmatic guide that will assist both beginning and experienced practitioners in establishing and operating a successful hospital epidemiology program. This handbook will supplement the various scientific references already available for this field and will help hospital epidemiologists improve their practices.

Mail order form to:

SLACK Incorporated, Professional Book Division, 6900 Grove Road, Thorofare, NJ 08086-9447

Call: (800) $257-8290$ or (856) $848-1000$

Fax: (856) 853-5991

E-mail: orders@slackinc.com

World Wide Web Site: http://www.slackinc.com 